\title{
Continuous Maize Cropping Accelerates Loss of Soil Organic Matter in Northern Thailand as Revealed by Natural 13C Abundance
}

\section{Kazumichi Fujii ( $\sim$ fkazumichi@affrc.go.jp )}

Forestry and Forest Products Research Institute https://orcid.org/0000-0001-9883-8044

\section{Risako Mitani}

Japan Women's University

Yoshiyuki Inagaki

Forestry and Forest Products Research Institute

\section{Chie Hayakawa}

Utsunomiya University

\section{Makoto Shibata}

Kyoto University

\section{Takashi Kosaki}

Aichi University

Miki Ueda

Japan Women's University

\section{Research Article}

Keywords: carbon sequestration, density fractionation, conventional tillage, shifting cultivation, soil organic matter

Posted Date: December 29th, 2021

DOI: https://doi.org/10.21203/rs.3.rs-1149438/v1

License: (c) (1) This work is licensed under a Creative Commons Attribution 4.0 International License. Read Full License

Version of Record: A version of this preprint was published at Plant and Soil on February 16th, 2022. See the published version at https://doi.org/10.1007/s11104-022-05333-4. 
$7 \quad{ }^{1}$ Forestry and Forest Products Research Institute, Tsukuba 305-8687, Japan.

$8 \quad{ }^{2}$ Faculty of Science, Japan Women's University, Tokyo 112-8681, Japan

$9{ }^{3}$ Faculty of Agriculture, Utsunomiya University, Utsunomiya 321-8505, Japan.

$10{ }^{4}$ Graduate School of Agriculture, Kyoto University, Kyoto 606-8502, Japan

$11{ }^{5}$ Faculty of International Communication, Aichi University, Nagoya 453-8777, Japan.

12

13 * Correspondence: K. FUJII, Forestry and Forest Products Research Institute, 1 Matsunosato,

14 Tsukuba, Ibaraki, 305-8687, Japan. Tel: +81-29-829-8228; Fax: +81-29-873-1542.

15 E-mail: fjkazumichi@gmail.com (K. Fujii)

16

17 Running title: Cultivation effects on soil carbon stocks

18 Keywords: carbon sequestration; density fractionation; conventional tillage; shifting 19 cultivation; soil organic matter 


\section{Abstract}

21 Aims: The loss of soil organic matter (SOM) has widely been reported in the tropics after

22 changing land use from shifting cultivation to continuous cropping. We tested whether

23 continuous maize cultivation accelerates SOM loss compared to upland rice and forest fallow.

24 Methods: Because litter sources include C4 plants (maize in maize fields and Imperata grass in

25 upland rice fields) in Thailand, C3-derived and C4-derived SOM can be traced using the

26 differences in natural ${ }^{13} \mathrm{C}$ abundance $\left(\delta^{13} \mathrm{C}\right)$ between $\mathrm{C} 3$ and $\mathrm{C} 4$ plants. We analyzed the effects

27 of land use history (cultivation or forest fallow period) on C stocks in the surface soil. Soil C

28 stocks decreased with the cultivation period in both upland rice and maize fields.

29 Results: The rate of soil organic carbon loss was higher in maize fields than in upland rice fields.

30 The decomposition rate constant (first order kinetics) of C3-plant-derived SOM was higher in

31 the maize fields than in the upland rice fields and the C4-plant-derived SOM in the forest fallow.

32 Soil surface exposure and low input of root-derived $\mathrm{C}$ in the maize fields are considered to

33 accelerate SOM loss. Soil C stocks increased with the forest fallow period, consistent with the

34 slow decomposition of C4-plant-derived SOM in the forest fallows.

35 Conclusions: Continuous maize cultivation accelerates SOM loss, while forest fallow and

36 upland rice cultivation could mitigate the SOM loss caused by continuous maize cultivation. 
40 In Southeast Asia, traditional shifting cultivation has been replaced by continuous cropping

41 systems (Kyuma and Pairintra, 1983). In northern Thailand, upland rice is cultivated between

42 forest fallow periods for subsistence, but continuous maize cultivation has increased along

43 paved roads with infrastructure improvement (Bruun et al., 2017). Intensive agriculture without

44 organic amendment leads to a loss of soil organic matter (SOM), which is essential for

45 increasing plant productivity and mitigating soil acidification (Kimetu et al., 2008; Fujii et al.,

46 2009; Jaiarree et al., 2011).

47 The intensification of agriculture, including tillage, generally risks increasing microbial

48 decomposition activities and soil erosion (Kimetu et al., 2008), but the impact could vary with

49 crop plants. Upland rice develops larger root systems than maize, especially under nitrogen and

50 water stress (Kondo et al., 2000). Because root litter is less decomposable than leaf litter (Fujii

51 et al., 2019), the lower shoot/root ratios of upland rice could provide greater root-derived C

52 input than maize of the same biomass (Kondo et al., 2000). In maize fields, the low root-derived

53 C input could limit the supply of SOM precursors, despite the high primary productivity

54 (Carvalho et al., 2017). Global assessment also suggests lower SOM stocks in maize fields

55 compared to other crops (West et al., 2002). We hypothesized that continuous maize cultivation

56 results in greater SOC loss compared to forest fallow or upland rice cultivation. 
58 inputs) and outputs (heterotrophic respiration, leaching, and erosion), the effects of land use on

59 SOM stocks can be quantified using annual soil C budgets (Fujii et al., 2009) or long-term

60 monitoring of soil organic carbon (SOC) stocks (Fujii et al., 2019, 2020). Alternatively, SOC

61 stocks can be compared between sites that share soil attributes with different land-use histories

62 (cultivation or fallow periods). Although our study site is in a remote part of northern Thailand,

63 its land-use history has been monitored continuously (Sakai, 2005; Fig. 1), enabling us to

64 compare the effects of land-use change on SOC stocks.

65 Continuous maize cropping results in a loss of forest-derived SOM and a gain of maize-

66 derived SOM. Because maize (C4 plant) and most woody species (C3 plants) have different

67 natural ${ }^{13} \mathrm{C}$ abundances $\left(\delta^{13} \mathrm{C}\right)$ due to their different photosynthetic pathways (Yoneyama et al.,

68 2006), C3-derived and C4-derived SOM can be traced in maize fields. In addition, while upland

69 rice is a C3 plant, the dominant weed (Imperata cylindrica) of upland rice fields is a C4 plant.

70 This allows us to trace the dynamics of C3- and C4-derived SOM under different fallow and

71 rice cultivation periods in northern Thailand. To test the hypothesis that continuous maize

72 cultivation results in greater SOC stock loss than forest fallow or upland rice cultivation, we

73 compared the SOM dynamics of forest fallow, upland rice, and maize fields. 


\section{Sampling soil material}

77 Soils were collected in 2014 in Ban Rakpaendin, Chiang Rai Province (195 50' N, $100^{\circ} 20^{\prime}$ E;

$78697 \mathrm{~m}$ a. s. 1.), where the mean annual air temperature is $25.0^{\circ} \mathrm{C}$ and the precipitation is 2084

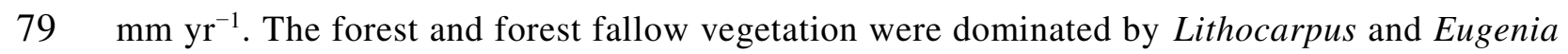

80 spp., with some planted rubber (Hevea brasiliensis) and orange (Citrus reticulata) trees. The

81 soils were clayey and classified as Typic Haplustults (Table 1; Soil Survey Staff, 2014). The

82 village land use has been affected by socio-economic development and political instability in

83 Indochina. Before the Indochina War, the Mieng (a hill tribe) conducted shifting cultivation of

84 upland rice (Sakai, 2005). After the war, northern Thai (Khon Muang) and Hmong migrated in

851982 and 1987, respectively, and started cultivating upland rice and maize in the upstream forest

86 (Fig. 1a). After the village protected the upstream forest for water security and a paved highway

87 was constructed in 1995, intensive maize cultivation expanded to the fields close to the highway

88 (Fig. 1a,b). The population increase and influx of refugees increased maize production. The

89 land use history has been recorded in the village (Fig. 1a,b). The cultivation and fallow periods

90 of the sampling locations were determined by interviews with farmers and a field survey, cross-

91 checked using satellite photos $(1992,2002,2007,2014)$ and a land use map (Sakai et al., 2005;

92 Fig. 1b). 


\section{Calculating the contributions of C3- and C4-plant-derived carbon}

95 The physical fractionation of soil is useful for tracing the pools of labile (free) and stable

96 (mineral-associated) SOM in the light and heavy fractions, respectively (Hassink, 1995; Tan et

97 al., 2007). The SOC in the two fractions was determined as follows. Briefly, $10 \mathrm{~g}$ of air-dried

98 soil was dispersed in a sodium iodide (NaI) solution $\left(1.60 \mathrm{~g} \mathrm{~cm}^{-3}\right)$, centrifuged at $2600 \mathrm{~g}$

99 (modified from Spycher et al., 1983), and the light $\left(<1.60 \mathrm{~g} \mathrm{~cm}^{-3}\right)$ and heavy $\left(>1.60 \mathrm{~g} \mathrm{~cm}^{-3}\right)$

100 fractions were recovered. The total $\mathrm{C}$ and $\mathrm{N}$ concentrations in soils were measured using a $\mathrm{CN}$

101 analyzer (Vario Max CN; Elementar Analysensysteme, Langenselbold, Germany).

102 Because the surface soil horizon is most sensitive to land use change in a soil profile

103 (Tan et al., 2007), this study focused on the $\mathrm{C}$ stocks in the top $0-5 \mathrm{~cm}$ of soil, which were

104 calculated as follows:

105 Soil C stock $(0-5 \mathrm{~cm})=$ Soil $C \times 0.05 \times 100 \times 100 \times$ Bulk density $/ 1000$

106 where the soil $\mathrm{C}$ stock $(0-5 \mathrm{~cm})\left(\mathrm{Mg} \mathrm{C} \mathrm{ha}^{-1}\right)$, soil $\mathrm{C}$ concentration in the light and heavy

107 fractions $\left(\mathrm{g} \mathrm{C} \mathrm{kg}^{-1}\right)$, surface $0-5-\mathrm{cm}$ soil volume $\left(\mathrm{m}^{-3}\right)(=0.05 \mathrm{~m} \times 100 \mathrm{~m} \times 100 \mathrm{~m})$, and bulk

108 density $\left(\mathrm{Mg} \mathrm{m}^{-3}\right)$ were measured using three replicates of a $0.1-\mathrm{L}$ core per plot.

109 The contributions of C3- and C4-plant-derived SOM to soil C were estimated using the 110 measured $\mathrm{C}$-isotope signatures $\left(\delta^{13} \mathrm{C}\right)$ and a mass balance approach (Nguyen-Sy et al., 2020). A 
111 sample $(\sim 50 \mu \mathrm{g} \mathrm{C})$ was weighed in a tin capsule and the $\delta^{13} \mathrm{C}$ isotope composition was measured

112 for the litter and soil samples using an online C analyzer (NC 2500; Thermo Fisher Scientific,

113 Waltham, MA, USA), coupled with an isotope ratio mass spectrometer (MAT252; Thermo

114 Electron, Bremen, Germany). All $\delta^{13} \mathrm{C}$ values are expressed relative to the international standard

115 Vienna Pee Dee Belemnite $(\mathrm{VPDB}): \delta^{13} \mathrm{C}=\left(\mathrm{R}_{\text {sample }} / \mathrm{R}_{\mathrm{VPDB}}-1\right)$. The standard deviation for four

116 replicate combustions of the same standard within a sequence was less than $0.10 \%$.

117 The sample $\delta^{13} \mathrm{C}$ values depend on the mixture of $\mathrm{C} 3$ plant-derived $\mathrm{C}$ and $\mathrm{C} 4$-plant-derived

118 C, as expressed in the following equation (Nguyen-Sy et al., 2020):

$$
\delta^{13} C(\text { Sample })=x \times \delta^{13} C(C 3)+(1-x) \times \delta^{13} C(C 4)
$$

120 where $\delta^{13} \mathrm{C}$ (sample) is the measured $\delta^{13} \mathrm{C}$ value of the sample, $\delta^{13} \mathrm{C}(\mathrm{C} 3)$ is derived from the

121 C3-plant-derived C (av. $-28.6 \%), \delta^{13} \mathrm{C}(\mathrm{C} 4)$ is derived from the C4-plant-derived C (av.

$122-12.5 \%$ ), and $x$ denotes the proportion of $\mathrm{C} 3$-plant-derived $\mathrm{C}$. The proportions of $\mathrm{C} 3$-plant-

123 derived C $(x)$ and C4-plant-derived C $(1-x)$ were estimated with the following equations:

$$
\begin{gathered}
\text { Proportion of } C 3 \text { derived } C=\frac{\delta^{13} C(\text { Sample })-\delta^{13} C(C 4)}{\delta^{13} C(C 3)-\delta^{13} C(C 4)} \\
\text { Proportion of } C 4 \text { derived } C=1-\frac{\delta^{13} C(\text { Sample })-\delta^{13} C(C 4)}{\delta^{13} C(C 3)-\delta^{13} C(C 4)}
\end{gathered}
$$

126 The SOM loss data were fitted to a single exponential decay function:

127

$$
R_{r} / R_{i}=e^{-k t}
$$


128 where $R_{\mathrm{r}}$ and $R_{\mathrm{i}}$ are the initial and remaining $\mathrm{C}$ stock $\left(\mathrm{Mg} \mathrm{C} \mathrm{ha}{ }^{-1}\right)$ respectively, $k$ is the 129 decomposition rate constant $\left(\mathrm{yr}^{-1}\right)$, and $t$ is the cultivation or fallow period ( $\mathrm{yr}$ ).

\section{$131 \quad$ Statistics}

132 All results are expressed on an oven-dried weight basis for soil samples $\left(105^{\circ} \mathrm{C}, 24 \mathrm{~h}\right)$ and plant

133 samples $\left(70^{\circ} \mathrm{C}, 48 \mathrm{~h}\right)$. Significant $(P<0.05)$ differences between the light and heavy fractions

134 or between land-use types in the soil $\mathrm{C}$ stocks, $\delta^{13} \mathrm{C}$ values, and decomposition rate constants

135 ( $k$ ) were tested using analysis of variance (ANOVA). The SOM loss data were fitted to Eq. 5

136 using the least-squares technique. The differences in the slopes of the linear regression

137 equations of SOM loss were compared between land-use types. All statistics were performed

138 using SigmaPlot 14.5 and tested at a significance level of 0.05, unless otherwise stated.

140 Results

\section{Characteristics of the litter and soil density fractions}

142 Soil C stocks were positively correlated with the forest fallow period (Fig. 2a). The annual gain

143 of $0.84 \mathrm{Mg} \mathrm{C} \mathrm{ha}^{-1} \mathrm{yr}^{-1}$ in soil corresponded to $16.2 \%$ of the annual litterfall $\mathrm{C}$ input in the forest

144 fallow (Table 1; Fig. 2a). By contrast, the soil C stocks were negatively correlated with the

145 cultivation period in both the upland rice and maize fields (Fig. 2b,c). Comparison of the slopes 
146 of the linear regressions indicated that the SOC loss rate was significantly $(P<0.05)$ higher in

147 the maize field than in the upland rice field (Fig. 2bc).

148 The $\delta^{13} \mathrm{C}$ values of Imperata grass and maize litter (C4 plants) differed significantly

149 from those of forest litter (C3 plants) (Table 1). This supports the precondition of our study that

150 C3 plant-derived and C4 plant-derived SOM can be traced in soils. The $\mathrm{C} / \mathrm{N}$ ratios and $\mathrm{C}$

151 concentrations were significantly $(P<0.05)$ lower in the heavy fractions than in the light

152 fractions (Table 2). The $\delta^{13} \mathrm{C}$ values in the heavy fraction were significantly $(P<0.05)$ higher

153 than in the light fraction in the forest soils, but no significant differences in the $\delta^{13} \mathrm{C}$ values

154 were found between the heavy and light fractions in the upland rice and maize fields (Table 2).

\section{Contribution of C3- or C4-plant-derived carbon to soil organic matter}

157 In both the upland rice and maize fields, the $\delta^{13} \mathrm{C}$ values in the light and heavy fractions were

158 positively correlated with cultivation period (Fig. 3a,b). By contrast, the $\delta^{13} \mathrm{C}$ values in the light

159 and heavy fractions of the forest sites were negatively correlated with the fallow period (Fig.

160 3a,b). C3-plant-derived C was dominant at all sites, but the respective proportions of C3-plant-

161 derived $\mathrm{C}$ decreased to $62 \%$ and $67 \%$ in the light and heavy fractions of the cropland soils. The

162 proportion of $\mathrm{C} 4$-plant-derived $\mathrm{C}$ in the light fractions increased from $10 \%$ to $38 \%$ in the maize

163 fields and from $8 \%$ to $24 \%$ in the upland rice field (Table 2). Similarly, the proportion of C4 - 
164 plant-derived $\mathrm{C}$ in the heavy fractions increased from $3 \%$ to $33 \%$ in the maize fields and from

$16511 \%$ to $32 \%$ in the upland rice field (Table 2). The C3-plant-derived C stock decreased with

166 cultivation period in the maize (Fig. 4a) and upland rice (Fig. 5a) fields. However, the

167 proportion of $\mathrm{C} 4$-plant-derived $\mathrm{C}$ in the heavy fraction decreased from $30 \%$ to $6 \%$ in the forest

168 fallow (Table 2). The total $\mathrm{C}$ stock in the soil increased with the fallow period in the forest

169 fallows, but the C4-plant-derived C stocks decreased (Fig. 5b).

170 Fitting the SOM loss data to an exponential decay gives the decomposition rate

171 constants or $k$ values, except for the light fraction of the forest sites (Table 3; Figs. 4a, 5a,b).

172 The $k$ value of the heavy fraction was significantly $(P<0.05)$ lower than that of the bulk soil

173 in the forest fallow sites (Table 3). By comparison, the $k$ value of the heavy fraction was

174 significantly $(P<0.05)$ higher than that of light fraction in both the upland rice and maize fields

175 (Table 3). The $k$ values of SOM decomposition in the bulk soil were in the order of maize field

$176(0.044)>$ upland rice field $(0.031)>$ forest $(0.020)$ (Table 3$)$.

178 Discussion

179 Effects of tillage on soil organic matter decomposability in different density fractions

180 SOM in the light fraction generally decomposes faster than SOM associated with minerals in

181 the heavy fraction (Hassink, 1995; Tan et al., 2007). Our study also showed that the C4-plant- 
182 derived SOM in the light fraction of forest fallow soils also decomposes faster than in the heavy

183 fraction (Table 3). The SOM in the heavy fraction has higher $\delta^{13} \mathrm{C}$ values and lower $\mathrm{C} / \mathrm{N}$ ratios

184 due to selective respiration of ${ }^{12} \mathrm{C}$ relative to ${ }^{13} \mathrm{C}$ (Table 2) and the higher degree of humification,

185 compared to the light fraction (Table 2; Wagai et al., 2020).

186 In the maize field, C3-plant-derived $\mathrm{C}$ in the heavy fraction decomposes faster than in

187 the light fraction (Table 3). This contrasts with reports that recalcitrant SOM in the heavy

188 fraction decomposes slowly (Hassink, 1995; Tan et al., 2007), but faster turnover of the heavy

189 fraction has also been reported (Crow et al., 2007). SOM turnover could vary, depending on

190 soil types and tillage practices (Gregorich et al., 1995; Sollins et al., 2009). Tillage and input

191 of accessible labile litter could stimulate microbial activity to decompose the humified SOM

192 (priming effects) in the heavy fraction for nutrient mining (Dimassi et al., 2014). Note that C3-

193 plant-derived SOM is not equal to forest-derived SOM in the maize fields, as C3 plant litter

194 inputs from weeds (e.g., Asteroideae spp.) could be supplied to C3-derived SOM in the maize

195 fields. This induces risk of underestimating the decomposition rate constants of the light

196 fraction. 
199 We hypothesized that continuous maize cultivation results in greater loss of SOC stocks

200 compared to forest fallow or upland rice cultivation. This is supported by the higher SOC loss

201 rate in the maize field than in the upland rice field (Fig. 2b,c) as well as higher rate constants

202 of C3-plant-derived SOM decomposition in the maize fields compared to C3-plant-derived

203 SOM decomposition in the upland rice fields and C3-plant-derived SOM decomposition in the

204 forest fallows (Table 3; Figs. 4, 5). This is consistent with a net $\mathrm{C}$ loss in the annual C balance

205 between litter inputs and heterotrophic respiration (Fujii et al., 2009) as well as a global

206 assessment reporting lower soil C stocks in maize fields compared to other crops (West et al., 207 2002).

208 The slower decomposition of C3-plant-derived SOM in the upland rice fields compared

209 to the maize fields (Table 3) is consistent with the lower SOM loss rates in upland rice fields

210 (Fig. 2b). As in the maize field, C3-plant-derived SOM is not equal to forest-derived SOM in

211 the upland rice fields, as upland rice-derived SOM could also be provided. Based on the lower

212 shoot/root ratios of upland rice, root-derived $\mathrm{C}$ inputs would be greater in the upland rice fields

213 than in the maize fields (Kondo et al., 2000). This could mitigate the loss of C3-plant-derived

214 SOM in the upland rice fields (Fig. 5a). The limited erosion due to rice straw covering the soil

215 surface could also mitigate SOM loss. 
217 upland rice was traditionally cultivated before forest fallow started (Sakai, 2005). SOM of C4

218 plant origin can decompose faster than SOM of C3 plant origin (Wynn and Bird, 2007).

219 However, the decomposition of C4-plant-derived SOM in the forest fallow is much slower than

220 the decomposition of C3-plant-derived SOM in the croplands in our study (Table 3). Potential

221 reasons for the preservation of C4-plant-derived SOM in forest fallow are aggregate formation

222 under no tillage, less erosion, and soil acidity (Gregorich et al., 1995; Fujii et al., 2019). As

223 seen in the lower decomposition rate constants of the heavy fraction (Table 3), no tillage

224 practice under forest fallow vegetation favors the development of aggregates and physical

225 protection of SOM in aggregates (Tan et al., 2007; Wagai et al., 2020). In addition, the forest

226 canopy can limit erosion by rainfall and temperature rise by sunlight (Pimentel and Kounang,

227 1998). Acidic soil limits cellulose decomposition in forest litters (Hayakawa et al., 2014; Fujii

228 et al., 2019).

230 Implications for sustainable soil management

231 SOM gain or loss is directly related to the $\mathrm{C}$ sink/source function of soil and indirectly affects

232 sustainable maize productivity via effects on soil acidity, because maize growth is sensitive to

233 acidity (Calba et al., 2006; Minasny et al., 2017). Soil pH increased with the C concentration in 
234 the heavy fraction of cropland soil (Fig. S1). SOM has two functions in $\mathrm{pH}$ control- $\mathrm{pH}$

235 buffering due to the weak acid nature of functional groups and consumption of protons via the

236 net mineralization of organic anions (Poss et al., 1995; Fujii et al., 2012). Soil acidification

237 under continuous cropping can be mitigated by the mineralization of SOM that has accumulated

238 under the forest fallow (Fujii et al., 2009, 2021). Therefore, a gain or loss of SOM leads to a

239 respective gain or loss of soil potential to neutralize acidity. The annual gain of $0.12 \mathrm{Mg} \mathrm{C} \mathrm{ha}^{-1}$

$240 \mathrm{yr}^{-1}$ in cropland soils corresponded to only $2.8 \%$ of the annual maize residue C input (Table 1;

241 Figs. 4c, Fig. S2c) compared to $16.2 \%$ of the annual litterfall $\mathrm{C}$ input in the forest fallow soils

242 (Table 1; Fig. 2a). Judging from the finding that soil $\mathrm{C}$ accumulation rates in the forest fallow

243 exceed SOM loss rates in the cropland soils (Fig. 2), forest fallow has high potential to mitigate

244 soil degradation. When we compare upland rice and maize, upland rice has slower rates of SOM

245 loss despite a similar gain rate of C4-plant-derived C in soil (Figs. 2b,c, Fig. S2c). Upland rice

246 cultivation and forest fallow both involve low soil disturbance, which favors the development

247 of soil aggregates and mitigation of erosion (Pimentel and Kounang, 1998). These SOM

248 preservation mechanisms should be applied to develop a land-use strategy to mitigate soil

249 degradation, such as agroforestry involving crop and rubber or orange trees. 


\section{Conclusions}

252 We showed quantitatively that continuous cropping of maize or upland rice leads to a loss of

253 SOC. Especially, continuous cropping causes a greater loss of SOC compared to upland rice

254 cultivation. The decomposition of C4-plant-derived SOM was slower in forest fallow than the

255 decomposition of C3-plant-derived SOM in maize or upland rice fields. Since the soil C stocks

256 increased with the forest fallow period and upland rice cultivation has a slower loss of SOC,

257 the inclusion of forest fallow and upland rice cultivation in a land-use strategy is optimal for

258 maintaining SOC stocks.

259

260 Acknowledgments

261 This work was financially supported by a Japan Society for the Promotion of Science (JSPS)

262 grant (No.11J05776), JST SICORP Grant Number JPMJSC19C3, Japan and JST Fusion

263 Oriented Research for destructive Science and Technology (FOREST) Grant No. 20351100.

264

265 Conflict of Interest: The authors declare that they have no conflict of interest 


\section{References}

267 Bruun TB, de Neergaard A, Burup ML, Hepp CM, Larsen MN, Abel C, Aumtong S, Mertz O

268 (2017) Intensification of upland agriculture in Thailand: Development or degradation?

269 Land Degrad. Develop., 28: 83-94.

270 Calba H, Zonkeng C, Ngonkeu ELM, Adetimirin VO, Mafouasson HA, Meka SS, Horst WJ

271 (2006) Responses of maize grain yield to changes in acid soil characteristics after soil

272 amendments. Plant Soil, 284: 45-57.

273 Crow SE, Swanston CW, Lajtha K, Brooks JR, Keirstead H (2007) Density fractionation of 274 forest soils: methodological questions and interpretation of incubation results and turnover 275 time in an ecosystem context. Biogeochemistry, 85: 69-90.

276 Dimassi B, Mary B, Fontaine S, Perveen N, Revaillot S, Cohan JP (2014) Effect of nutrients 277 availability and long-term tillage on priming effect and soil C mineralization. Soil Biol. 278 Biochem., 78: 332-339.

279 Fujii K, Funakawa S, Hayakawa C, Kosaki T (2009) Quantification of proton budgets in soils 280 of cropland and adjacent forest in Thailand and Indonesia. Plant Soil, 316: 241-255.

281 Fujii K, Funakawa S, Kosaki T (2012) Soil acidification: Natural process and human impacts. 282 Pedologist, 55: 415-425. 
283 Fujii K, Hayakawa C, Inagaki Y, Kosaki T (2019) Effects of land use change on turnover and 284 storage of soil organic matter in a tropical forest. Plant Soil, 446: 425-439.

285 Fujii K, Morioka K, Hayakawa C, Inagaki Y, Hangs RD, Anderson DW, McConkey BG (2020)

286 Litter decomposition and soil organic carbon stabilization in a Kastanozem of

287 Saskatchewan, Canada. Geoderma Regional, 23: e00348.

288 Fujii K, Toma T, Sukartiningsih (2021) Comparison of soil acidification rates under different 289 land uses in Indonesia. Plant Soil 1-17.

290 Gregorich EG, Monreal CM, Ellert BH (1995) Turnover of soil organic matter and storage of 291 corn residue carbon estimated from natural ${ }^{13} \mathrm{C}$ abundance. Can. J. Soil Sci., 75: 161-167.

292 Hayakawa C, Funakawa S, Fujii K, Kadono A, Kosaki T (2014) Effects of climatic and soil 293 properties on cellulose decomposition rates in temperate and tropical forests. Biol. Fertil. 294 Soils, 50: 633-643.

295 Hayakawa C, Fujii K, Funakawa S, Kosaki T (2018) Effects of sorption on biodegradation of 296 low-molecular-weight organic acids in highly-weathered tropical soils. Geoderma, 324: $297 \quad 109-118$.

298 Hassink J (1995) Decomposition rate constants of size and density fractions of soil organic 299 matter. Soil Sci. Soc. Am. J., 59: 1631-1635. 
300 Jaiarree, S., Chidthaisong, A., Tangtham, N., Polprasert, C., Sarobol, E., Tyler, S. C. (2011) Soil

301 organic carbon loss and turnover resulting from forest conversion to maize fields in Eastern

302 Thailand. Pedosphere, 21: 581-590.

303 Kallenbach CM, Frey SD, Grandy AS (2016) Direct evidence for microbial-derived soil organic

304 matter formation and its ecophysiological controls. Nature Commun. 7: 13630.

305 Kimetu JM, Lehmann J, Ngoze SO, Mugendi DN, Kinyangi JM, Riha S, Verchot L, Recha, JW,

306 Pell AN (2008) Reversibility of soil productivity decline with organic matter of differing

307 quality along a degradation gradient. Ecosystems, 11: 726-739.

308 Kondo M, Murty MV, Aragones DV (2000) Characteristics of root growth and water uptake

309 from soil in upland rice and maize under water stress. Soil Sci. Plant Nutr., 46: 721-732.

310 Minasny B, Malone BP, McBratney AB, Angers DA, Arrouays D, Chambers A, Field DJ (2017)

311 Soil carbon 4 per mille. Geoderma, 292: 59-86.

312 Nguyen-Sy T, Cheng W, Kimani SM, Shiono H, Sugawara R, Tawaraya K, Watanabe T,

313 Kumagai K (2020) Stable carbon isotope ratios of water-extractable organic carbon affected

314 by application of rice straw and rice straw compost during a long-term rice experiment in

315 Yamagata, Japan. Soil Sci. Plant Nutr., 66: 125-132.

316 Pimentel D, Kounang N (1998) Ecology of soil erosion in ecosystems. Ecosystems, 1: 416-426. 
317 Poss R, Smith C J, Dunin F X, Angus JF (1995) Rate of soil acidification under wheat in a semi 318 arid environment. Plant Soil, 177: 85-100.

319 Kyuma K, Pairintra C (1983) Shifting cultivation. An Experiment at Nam Phrom, Northeast

320 Thailand, and Its Implications for Upland Farming in the Monsoon Tropics. Kyoto 321 University, Kyoto, Japan.

322 Sakai Y (2005) People's response activities for environmental degradations and roles of 323 outsiders: a case study in the mountainous northern Thailand. Kyoto University (in 324 Japanese).

325 Soil Survey Staff (2014) Keys to Soil Taxonomy, Twelfth Edition. United States Department of 326 Agriculture Natural Resources Conservation Service, Washington, D.C.

327 Sollins P, Kramer MG, Swanston C, Lajtha K, Filley T, Aufdenkampe AK, Wagai R, Bowden 328 RD (2009) Sequential density fractionation across soils of contrasting mineralogy: evidence 329 for both microbial-and mineral-controlled soil organic matter stabilization. $330 \quad$ Biogeochemistry, 96: 209-231.

331 Spycher G, Sollins P, Rose S (1983) Carbon and nitrogen in the light fraction of a forest soil:

$332 \quad$ vertical distribution and seasonal patterns. Soil Sci., 135: 79-87.

333 Tan Z, Lal R, Owens L, Izaurralde RC (2007) Distribution of light and heavy fractions of soil 334 organic carbon as related to land use and tillage practice. Soil Till. Res., 92: 53-59. 
335 Wagai R, Kajiura M, Asano M (2020) Iron and aluminum association with microbially

336 processed organic matter via meso-density aggregate formation across soils: organo-

337 metallic glue hypothesis. Soil, 6: 597-627.

338 West TO, Post WM (2002) Soil organic carbon sequestration rates by tillage and crop rotation:

339 a global data analysis. Soil Sci. Soc. Am. J., 66: 1930-1946.

340 Wynn JG, Bird MI (2007) C4-derived soil organic carbon decomposes faster than its C3

341 counterpart in mixed C3/C4 soils. Glob. Chan. Biol., 13: 2206-2217.

342 Yoneyama T, Okada H, Chongpraditnum P, Ando S, Prasertsak P, Hirai K (2006) Effects of

343 vegetation and cultivation on $\delta 13 \mathrm{C}$ values of soil organic carbon and estimation of its

344 turnover in Asian tropics: a case study in Thailand. Soil Sci. Plant Nutr., 52: 95-102.

346 Table captions

347 Table 1 Site information of litter and soil

349 Table 2 Soil $\mathrm{C}$ stocks and ${ }^{13} \mathrm{C}$ natural abundance in light and heavy fractions

351 Table 3 Decomposition rate constants of C3 or C4 plant-derived organic matter in the light and 352 heavy fractions 


\section{$353 \quad$ Figure captions}

354 Fig. 1 (a) Land use change from shifting cultivation in the upstream area to continuous cropping

355 in the downstream area close to highway, (b) land use map in 1992 and 2004, and (c) sampling

356 locations on topographic map (contours with 50m interval). Data source was Sakai (2005).

358 Fig. 2 Changes in soil carbon stocks $(0-5 \mathrm{~cm})$ of (a) forest fallow, (b) upland rice field, and (c)

359 maize field.

360

361 Fig. 3 Changes in soil $\delta^{13} \mathrm{C}$ values of (a) light fraction and (b) heavy fraction of the surface soil 362 (b).

364 Fig. 4 Changes in stocks $(0-5 \mathrm{~cm})$ of (a) C3-plant-derived C (bulk soil), (b) C3-plant-derived C

365 in the light and heavy fractions, (c) C4-plant-derived C (bulk soil), and (d) C4-plant-derived C

366 in the light and heavy fractions in the maize fields. The curves represent fitting with single

367 exponential decay function, while lines represent fitting with single linear regression. 
369 Fig. 5 Changes in stocks $(0-5 \mathrm{~cm})$ of (a) C4-plant-derived C (bulk soil) in the forest fallows and

370 (b) C3-plant-derived C (bulk soil) in the upland rice fields. The curves represent fitting with

371 single exponential decay function.

372

373 Fig. S1 Relationship between soil $\mathrm{pH}$ and soil $\mathrm{C}$ concentration in the heavy fraction $(>1.60 \mathrm{~g}$ $\left.374 \mathrm{~cm}^{-3}\right)$.

375

376 Fig. S2 Changes in stocks $(0-5 \mathrm{~cm})$ of (a) forest-derived C (bulk soil), (b) forest-derived C in

377 the light and heavy fractions, (c) C4-plant-derived C (bulk soil), and (d) C4-plant-derived C in

378 the light and heavy fractions in the upland rice fields. The curves represent fitting with single

379 exponential decay function, while lines represent fitting with single linear regression. 


\section{Figures}

(a)

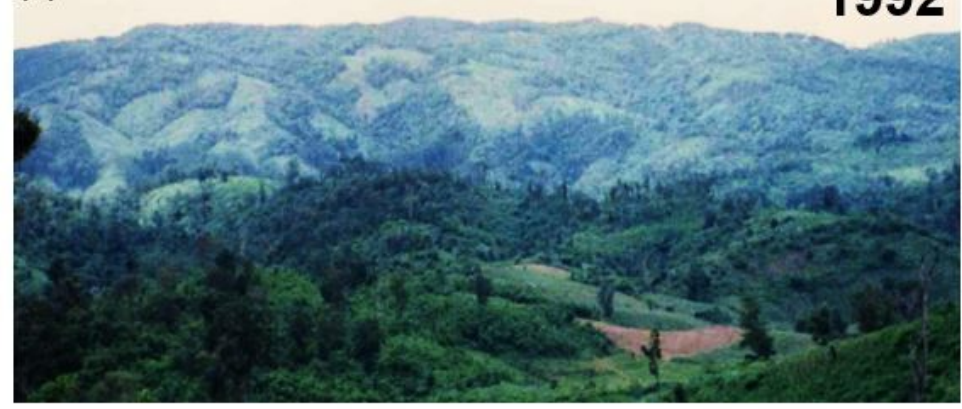

2004
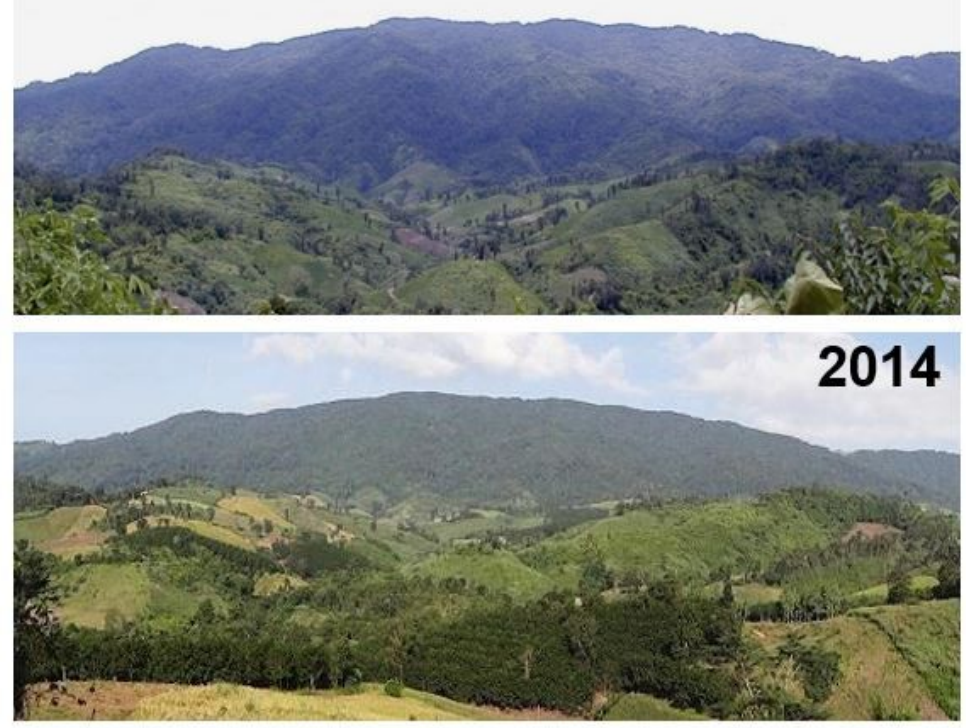
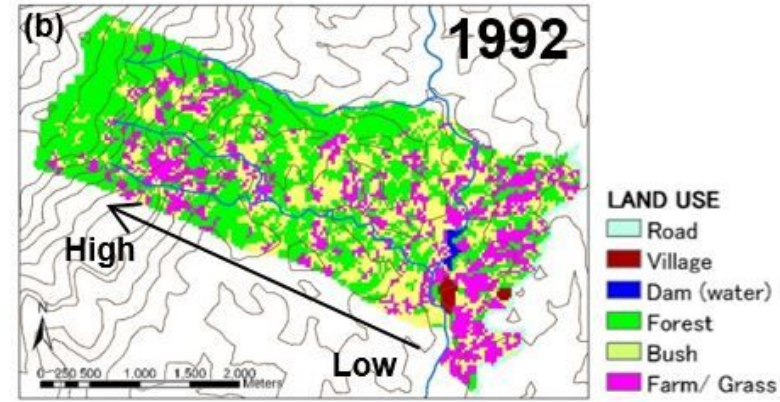

2004
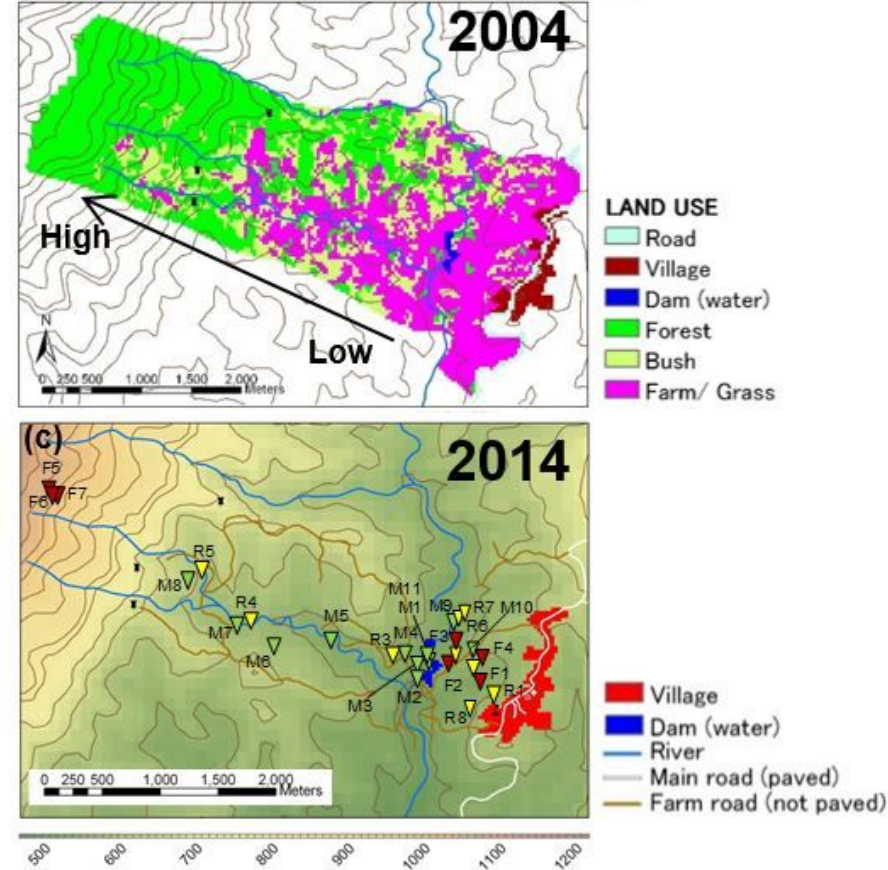

Figure 1

(a) Land use change from shifting cultivation in the upstream area to continuous cropping in the downstream area close to highway, (b) land use map in 1992 and 2004, and (c) sampling locations on topographic map (contours with $50 \mathrm{~m}$ interval). Data source was Sakai (2005). 
(a) Forest fallow

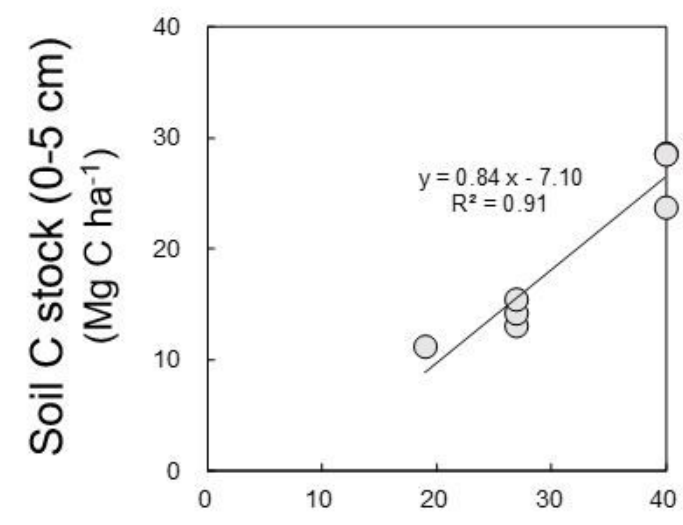

Fallow period $(\mathrm{yr})$ (b) Upland rice

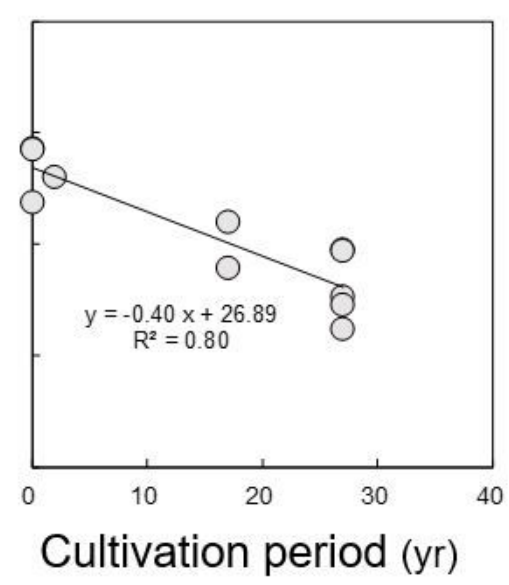

(c) Maize

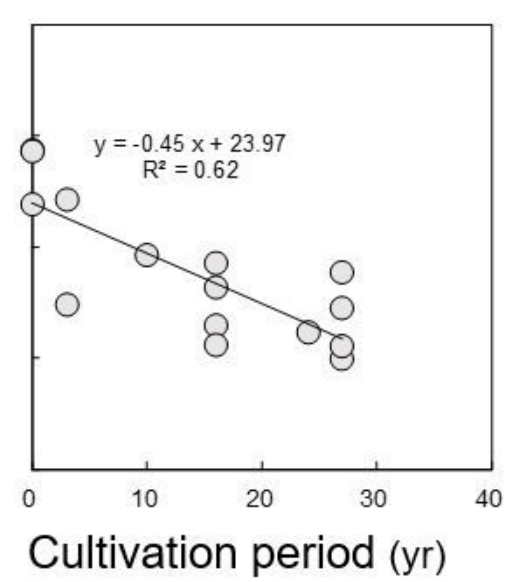

Figure 2

Changes in soil carbon stocks $(0-5 \mathrm{~cm})$ of (a) forest fallow, (b) upland rice field, and (c) maize field.

(a) Light fraction

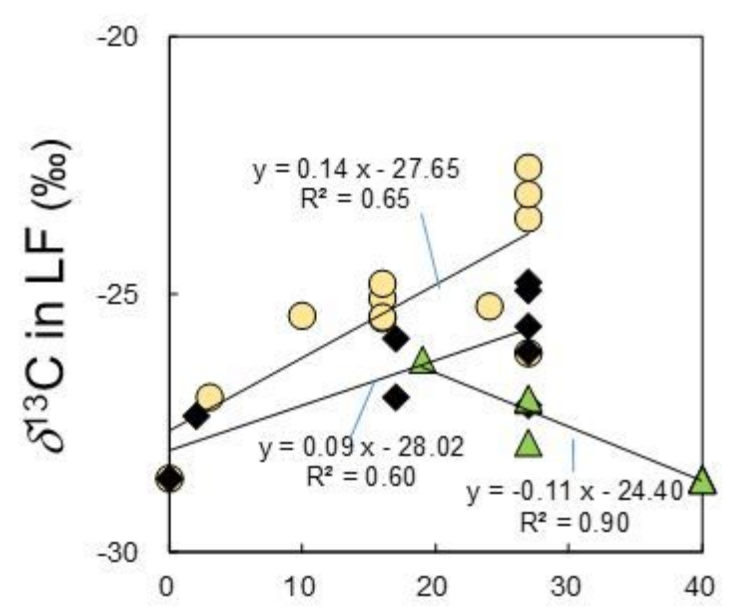

Fallow or cultivation period (yr) (b) Heavy fraction

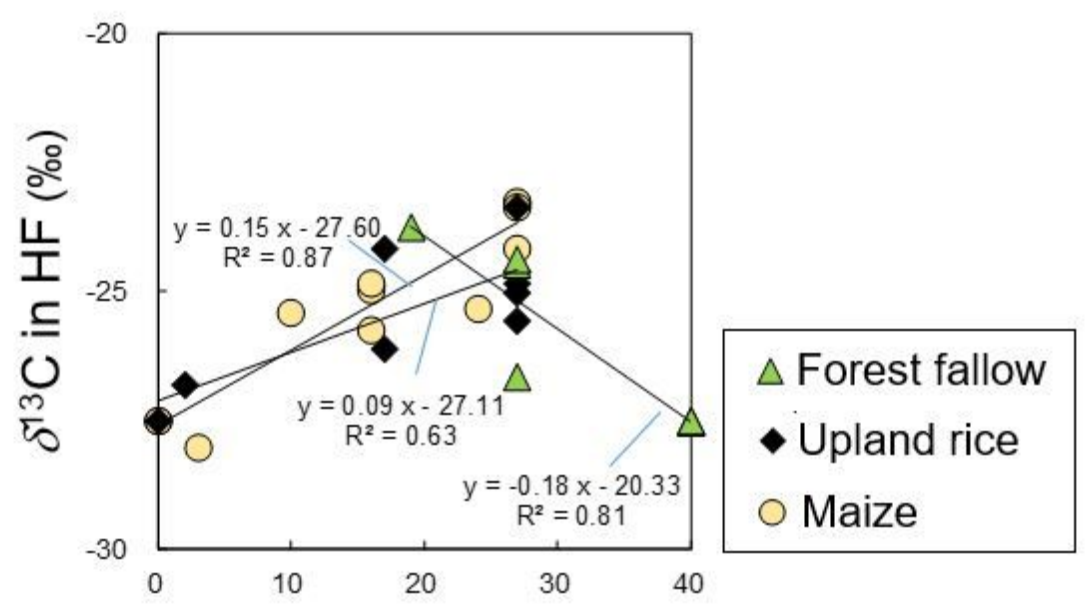

Fallow or cultivation period (yr)

Figure 3

Changes in soil $d^{13} \mathrm{C}$ values of (a) light fraction and (b) heavy fraction of the surface soil (b). 
(a) Total C3-plant-derived C (b) C3-plant-derived C in LF and HF
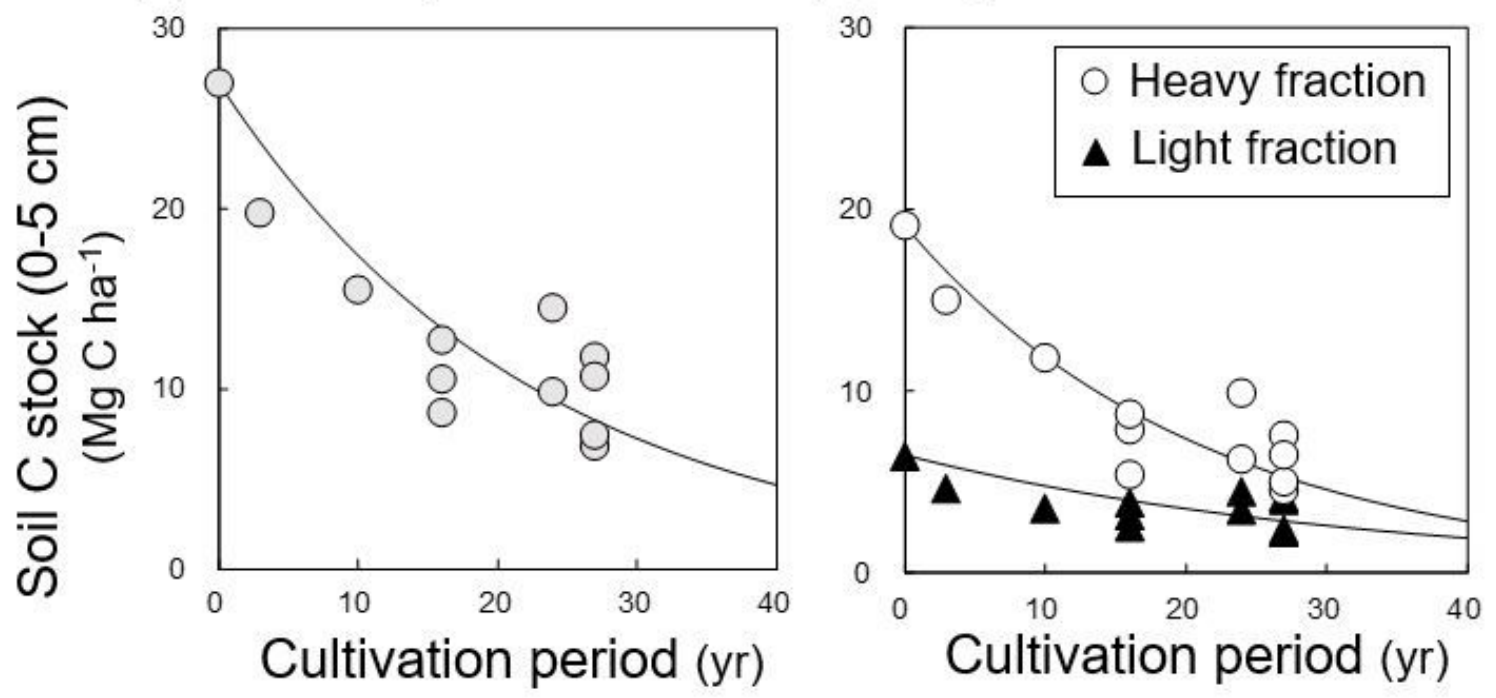

(c) Total C4-plant-derived C

(d) C4-plant-derived C in LF and HF
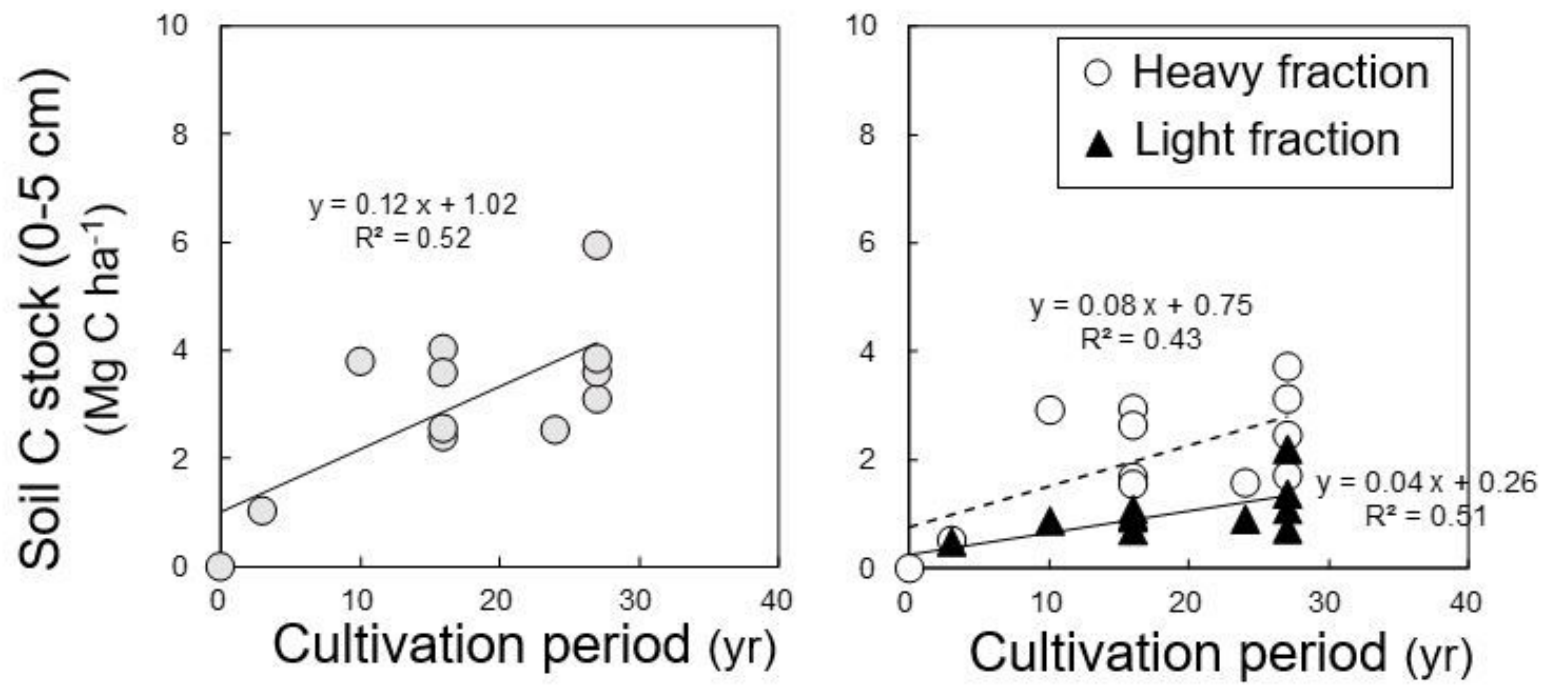

Figure 4

Changes in stocks ( $0-5 \mathrm{~cm}$ ) of (a) C3-plant-derived C (bulk soil), (b) C3-plant-derived $\mathrm{C}$ in the light and heavy fractions, (c) C4-plant-derived C (bulk soil), and (d) C4-plant-derived C in the light and heavy fractions in the maize fields. The curves represent fitting with single exponential decay function, while lines represent fitting with single linear regression. 

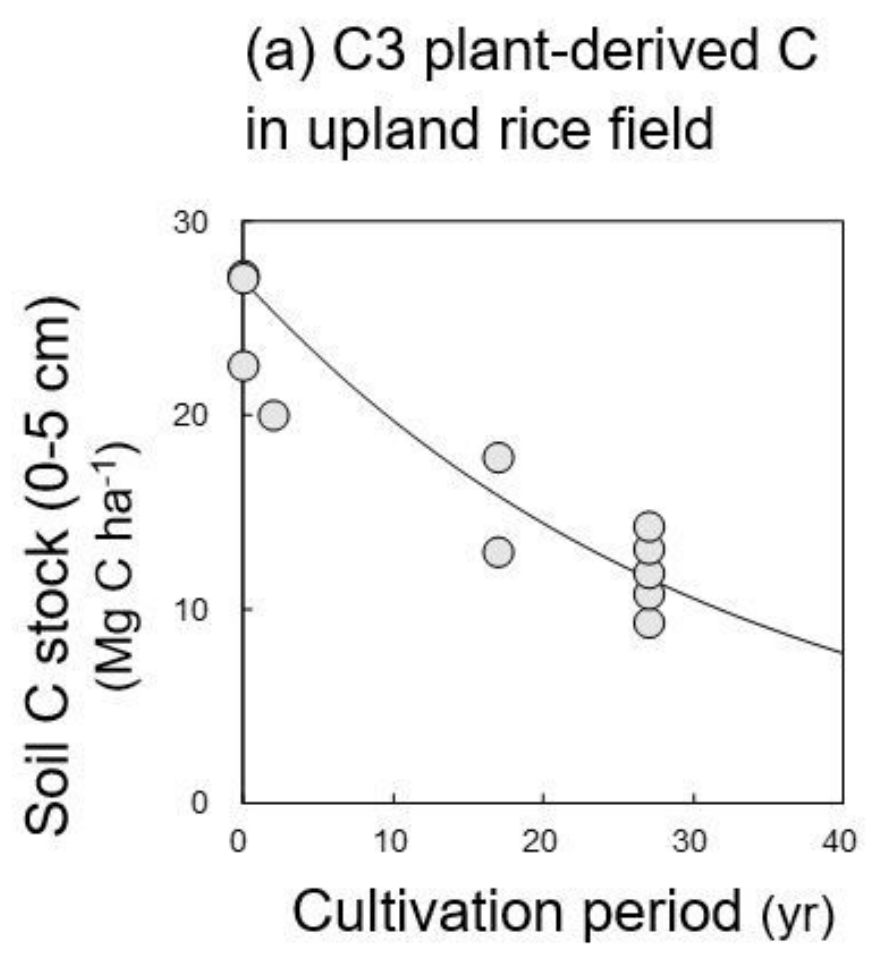

(b) C4 plant-derived C in forests

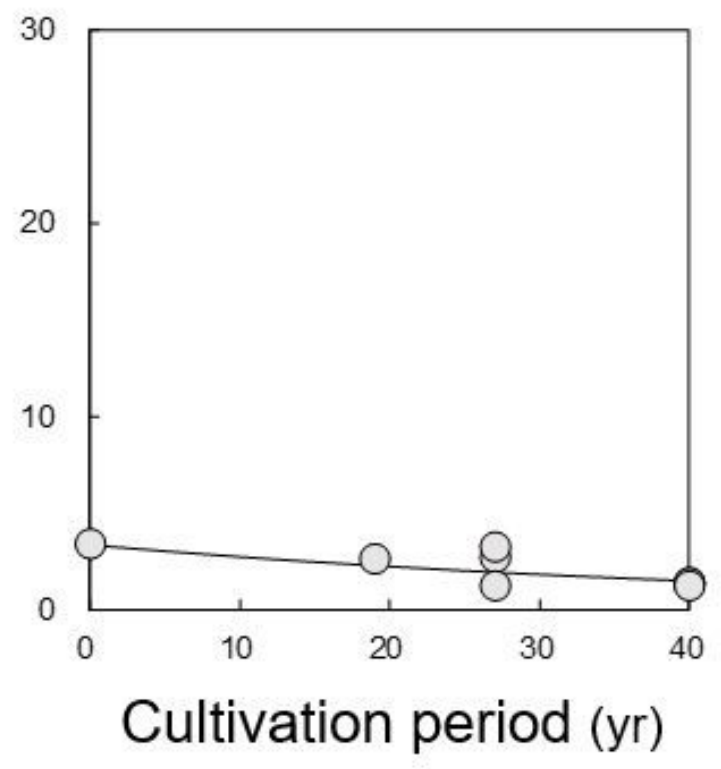

Figure 5

Changes in stocks $(0-5 \mathrm{~cm}$ ) of (a) C4-plant-derived C (bulk soil) in the forest fallows and (b) C3-plantderived $\mathrm{C}$ (bulk soil) in the upland rice fields. The curves represent fitting with single exponential decay function.

\section{Supplementary Files}

This is a list of supplementary files associated with this preprint. Click to download.

- Tables.pptx

- s1.jpg

- s2.jpg 